\title{
Sulfur Nutrition Affects Nonstructural Water-soluble Carbohydrates in Onion Germplasm
}

\author{
William M. Randle \\ Department of Horticulture, University of Georgia, Athens, GA 30602 \\ Additional index words. Allium cepa, sucrose, fructose, glucose, fructans, breeding, \\ selection
}

\begin{abstract}
Sixty onion (Allium cepa L.) entries were evaluated for nonstructural watersoluble carbohydrates (NWSC) under high $\left(4.0 \mathrm{meq}^{\cdot} \cdot \mathrm{liter}^{-1}\right)$ and low $\left(0.1 \mathrm{meq} \cdot \mathrm{liter}^{-1}\right)$ $S$ nutrition. Significant differences were detected among entries for sucrose, fructose, glucose, total fructans, total NWSC, and soluble solids content (SSC). Sucrose, total fructans, and SSC were highly correlated with total NWSC although deviant NWSC concentration was detected. Since a significant $S \times$ entry interaction was found for all NWSC concentrations tested. selection should be conducted at $S$ concentrations indicative of targeted production areas.
\end{abstract}

Bulb quality influences onion consumer acceptance. Preference for traits contributing to bulb quality depends on cultural demand and intended use (Jones and Mann, 1963; Rabinowitch, 1988). Sweet, low-pungency onions have long been appreciated in the United States, and recent increases in demand have been accompanied by increased interest in growing and breeding these onions. For the sweetness in onions to be tasted, the dominant effect of pungency must be minimized. Pungency is minimized by growing cultivars with the genetic potential for low pungency on low-S soils.

Nonstructural water-soluble carbohydrates (NWSC), which contribute to sweetness in onions, are a major component of the bulb, ranging from $41 \%$ to $88 \%$ of the total dry weight (Bajaj et al., 1980; Darbyshire and Henry, 1979; Suzuki and Cutcliffe, 1989). The major NWSC are sucrose, fructose, glucose, and fructans, a series of fructosyl polymers based on sucrose with varying degrees of polymerization (Bacon, 1957; Bose and Shrivastava, 1961; Darbyshire and Henry, 1978). The type of NWSC that accumulates depends on location within the bulb (Darbyshire and Henry, 1978). Fructans and sucrose are found in highest concentration in the center youngest leaves, near the true stem, whereas reducing sugars are highest in the older, outer leaf bases, near the top of the bulb. Bulb NWSC concentrations deviated little during the maturation period (Nilsson, 1980).

Onion cultivars differ in NWSC concentration and composition. As dry weight increased among 10 cultivars, fructose and glucose decreased, whereas sucrose and fructans increased (Darbyshire and Henry, 1979). Reducing and nonreducing sugars

Received for publication 11 Mar. 1991. Accepted for publication 15 Aug. 1991. The cost of publishing this paper was defrayed in part by the payment of page charges. Under postal regulations, this paper therefore must be hereby marked advertisement solely to indicate this fact. varied among cultivars within a narrow range of dry-matter percentages (Bajaj et al., 1980). Commercial onions are normally grown on soils with sufficient $S$ to provide the need for both growth and flavor precursor accumulation (Lancaster and Boland, 1988). Sulfur nutrition, however, was shown to affect bulb yield and total dry-matter accumulation in onions. Paterson (1979) reported a $10 \%$ increase in bulb yield when plants were grown on a Texas fine sandy loam and fertilized with $\mathrm{S}$ at $5.5 \mathrm{~kg} \cdot \mathrm{ha}^{-1}$ compared to 1.8 $\mathrm{kg} \cdot \mathrm{ha}^{-1}$. In another study, nutrient solutions deficient in $\mathrm{S}$ or with $\mathrm{S}$ at $0.05 \mathrm{meq} \cdot \mathrm{liter}^{-1}$ reduced plant growth (Freeman and Mossadeghi, 1970). Dry weight/plant was highest when $S$ ranged between 0.1 and 1.0 meq-liter ${ }^{-1}$ in the nutrient solutions, but plant fresh weight (grams) and leaf growth (centimeters) was highest when $\mathrm{S}$ ranged between 1.0 and 3.0 meq.liter ${ }^{-1}$. In any event, low amounts of $\mathrm{S}$ were sufficient to sustain onion growth.

To facilitate the breeding of sweet, lowpungency onions for production on low-S soils, an understanding of the extent of variation for NWSC in onion germplasm would be useful. In addition, knowledge of how these sugars vary among onion germplasm in response to $S$ nutrition would demarcate genotype x S interactions. This study was initiated to investigate how onion germplasm of broad genetic background responds to high and low S nutrition in NWSC accumulation.

An evaluation of NWSC was conducted on 34 U.S. plant introductions (PI) from the Northeastern Regional Plant Introduction Station, Geneva, N.Y.; on 24 accessions from the National Institute of Agricultural Science, Japan; and on two commercial cultivars. The germplasm was collected to represent a broad base of short- and intermediate-day types. However, upon growing, several of the PIs were long-day types. Seed of each entry were sown in Fafard \#3 artificial medium (Fafard Corp., Anderson, S.C.) in plastic trays on 15 Dec. Plants were grown in a greenhouse under natural photoperiods and light intensities with night and day temperatures set at 16 and $28 \mathrm{C}$, respectively. When the first true leaf emerged, seedlings were fertilized with half-strength Hoagland and Arnon (1950) solution. Seedlings were transplanted on $7 \mathrm{Feb}$. to 0.75 -liter pots containing the same media. The experimental design was a split pot in three replications with five pots per replication. Sulfur treatments were main plots and entries were subplots. A full-strength Hoagland's solution with $\mathrm{S}$ at $4 \mathrm{meq} \cdot \mathrm{liter}^{-1}$ was the high concentration; the low one was a modified Hoagland's solution with $\mathrm{S}$ at $0.1 \mathrm{meq} \cdot \mathrm{liter}^{-1}$. A S concentration of $<0.1$ meq.liter ${ }^{-1}$ has been shown to reduce growth by up to $50 \%$ in 'White Lisbon' (Freeman and Mossadeghi, 1970). Magnesium chloride was substituted for magnesium sulfate in the modified Hoagland's solution. Sulfuric acid was the S source. The $\mathrm{pH}$ of both solutions was adjusted to 6.5 with $\mathrm{NaOH}$. Plants were watered twice weekly with the nutrient solutions, supplemented with tap water as needed, and the pots were leached once a week. Sulfur concentration of the tap water was $<0.05 \mathrm{meq} \cdot \mathrm{liter}^{-1}$.

Plants were grown to maturity, characterized by a softening of the leaf sheath area and lodging of the foliage. Growth in the greenhouse was typical of field-grown plants. Replications were considered harvestable when the foliage lodged on four of the five plants. The earliest entry was mature on 1 May and the latest one on 21 June. Irrigation was withheld and the plants were allowed to dry for 7 days before the bulbs were harvested and the foliage and roots severed. The bulbs were then cured in paper bags at ambient greenhouse temperatures for 7 days and stored at room temperature for 30 days before NWSC analysis.

Sucrose, fructose, glucose, and total fructans were determined by the modified methods of Blakeney and Mutton (1980) and Pontis (1966). Samples were prepared by removing the dried outer scales, root plate, and neck of the bulbs. Five bulb samples were then quartered, added to equivalent weights of water, and blended for $60 \mathrm{sec}$ in a Waring blender. The resulting pulp was squeezed through cheesecloth, and a sample of juice was double-precipitated in a barium hydroxide solution $\left(57 \mathrm{~g} \cdot\right.$ liter $\left.^{-1}\right)$ followed by a zinc sulfate solution $\left(50 \mathrm{~g} \cdot \mathrm{liter}^{-1}\right)$. A benzoic acid solution ( $3 \mathrm{~g} \cdot$ liter $\left.^{-1}\right)$ was added and the mixture was filtered through a Whatman no. 4 filter paper. Sucrose and total reducing sugars were determined before and after invertase digestion using $p$-hydroxybenzoic acid hydrazide. Total fructose (free fructose, fructose in sucrose, and fructose in fructans) was determined using 2-thiobarbituric acid. Total fructans were determined by first removing the interference of free fructose and fructose from sucrose. The samples were incubated with invertase. Sodium hydroxide was added and the solutions heated, thereby destroying the free fructose. Total fructans were then estimated using 2-thiobarbituric acid. Sucrose, fructose, and glucose were calculated in the following way: sucrose = total reducing sugars (TRS) with invertase 
Table 1. Means for sucrose, fructose, glucose, fructans, total nonstructural water-soluble carbohydrates (NWSC), and soluble solids content (SSC) for onion germplasm grown under high $\left(4.0 \mathrm{meq} \cdot \mathrm{liter}^{-1}\right)$ and low $\left(0.1 \mathrm{meq} \cdot \mathrm{liter}^{-1}\right) \mathrm{S}$ nutrient regimes.

\begin{tabular}{|c|c|c|c|c|c|c|c|c|c|c|c|c|}
\hline \multirow[b]{2}{*}{ Entry ${ }^{2}$} & \multicolumn{2}{|c|}{ Sucrose } & \multicolumn{2}{|c|}{ Fructose } & \multicolumn{2}{|c|}{$\begin{array}{c}\text { Glucose } \\
(\mathrm{g} / 100 \mathrm{~g} \text { fresh } w t)\end{array}$} & \multicolumn{2}{|c|}{ Fructan } & \multicolumn{2}{|c|}{ NWSC } & \multicolumn{2}{|c|}{$\begin{array}{l}\text { SSC } \\
(\%)\end{array}$} \\
\hline & High S & Low $S$ & High S & Low $S$ & High $\mathbf{S}$ & Low S & High S & Low $S$ & High S & Low S & High S & Low S \\
\hline PI 168960 & 11.30 & 7.72 & 1.43 & 1.73 & 0.71 & 0.30 & 6.65 & 3.80 & 20.10 & 13.55 & 18.4 & 14.0 \\
\hline PI 168961 & 8.18 & 9.20 & 1.83 & 1.23 & 0.73 & 1.09 & 4.67 & 4.88 & 15.42 & 16.40 & 14.8 & 15.6 \\
\hline PI 172701 & 8.03 & 8.68 & 1.48 & 0.60 & 0.58 & 1.29 & 5.27 & 5.31 & 15.36 & 15.88 & 15.2 & 15.6 \\
\hline PI 174019 & 5.82 & 4.49 & 0.46 & 2.37 & 1.07 & 0.30 & 6.76 & 4.27 & 14.11 & 11.44 & 14.8 & 12.4 \\
\hline PI 177244 & 7.39 & 8.64 & 1.31 & 1.88 & 0.14 & 0.31 & 7.82 & 7.92 & 16.66 & 18.75 & 16.8 & 16.6 \\
\hline PI 181008 & 7.50 & 6.53 & 1.11 & 0.58 & 1.10 & 1.74 & 2.40 & 2.79 & 12.10 & 11.65 & 12.0 & 12.0 \\
\hline PI 182138 & 8.36 & 8.57 & 1.53 & 1.24 & 0.61 & 0.91 & 8.90 & 7.91 & 19.41 & 18.63 & 19.2 & 18.4 \\
\hline PI 223326 & 5.53 & 5.89 & 0.42 & 0.25 & 1.10 & 2.76 & 5.11 & 3.22 & 12.16 & 12.13 & 12.8 & 12.2 \\
\hline PI 234595 & 4.90 & 6.24 & 1.38 & 0.56 & 2.00 & 2.47 & 1.79 & 2.98 & 10.07 & 12.22 & 10.4 & 12.4 \\
\hline PI 247067 & 6.08 & 5.16 & 0.05 & 0.24 & 2.79 & 2.30 & 3.97 & 3.53 & 12.89 & 11.23 & 12.8 & 12.2 \\
\hline PI 249540 & 6.49 & 3.35 & 0.60 & 0.18 & 2.32 & 1.57 & 3.10 & 1.23 & 12.51 & 6.32 & 12.8 & 12.4 \\
\hline PI 251021 & 4.06 & 3.58 & 2.29 & 2.06 & 3.35 & 3.11 & 1.78 & 1.51 & 11.49 & 10.26 & 11.2 & 12.2 \\
\hline PI 256322 & 6.88 & 6.76 & 0.47 & 0.26 & 1.59 & 1.94 & 3.88 & 3.62 & 12.83 & 12.59 & 12.8 & 12.0 \\
\hline PI 260793 & 5.95 & 7.69 & 0.39 & 0.64 & 1.39 & 1.80 & 2.70 & 4.61 & 10.43 & 14.73 & 10.8 & 10.4 \\
\hline PI 261768 & 6.48 & 4.97 & 0.70 & 0.54 & 1.90 & 2.23 & 2.44 & 1.64 & 11.53 & 9.38 & 11.6 & 12.4 \\
\hline PI 262919 & 5.38 & 6.46 & 0.41 & 1.02 & 2.69 & 1.59 & 2.62 & 2.71 & 11.10 & 11.78 & 11.2 & 13.6 \\
\hline PI 272255 & 1.40 & 1.46 & 2.07 & 2.03 & 1.90 & 1.81 & 0.26 & 0.38 & 5.63 & 5.68 & 6.2 & 11.2 \\
\hline PI 274781 & 5.89 & 7.33 & 0.85 & 0.23 & 1.84 & 2.10 & 3.13 & 5.08 & 11.72 & 14.75 & 12.0 & 7.4 \\
\hline PI 342941 & 2.57 & 1.95 & 1.63 & 1.63 & 2.31 & 1.59 & 1.35 & 1.35 & 7.86 & 6.52 & 8.2 & 8.8 \\
\hline PI 344257 & 5.02 & 5.38 & 0.73 & 1.58 & 1.88 & 1.35 & 7.24 & 6.92 & 14.87 & 15.22 & 14.8 & 14.8 \\
\hline PI 344390 & 4.15 & 4.32 & 2.46 & 1.64 & 2.26 & 2.08 & 1.70 & 2.47 & 10.57 & 10.50 & 10.4 & 10.4 \\
\hline PI 351138 & 9.50 & 7.29 & 1.29 & 0.98 & 1.32 & 1.90 & 5.70 & 5.63 & 17.81 & 15.80 & 16.0 & 15.2 \\
\hline PI 354086 & 6.04 & 7.72 & 1.53 & 1.47 & 0.93 & 1.86 & 5.25 & 6.36 & 13.76 & 17.41 & 14.0 & 10.8 \\
\hline PI 354088 & 6.04 & 6.86 & 0.94 & 1.39 & 1.86 & 2.08 & 3.77 & 4.81 & 12.61 & 15.14 & 12.8 & 14.2 \\
\hline PI 354092 & 8.75 & 5.54 & 3.52 & 1.51 & 0.35 & 1.44 & 4.13 & 2.50 & 16.76 & 10.97 & 14.8 & 10.8 \\
\hline PI 414931 & 2.46 & 2.23 & 1.73 & 1.64 & 1.84 & 1.53 & 0.88 & 0.52 & 6.91 & 5.92 & 7.2 & 6.8 \\
\hline PI 430371 & 3.78 & 2.49 & 2.33 & 3.01 & 0.58 & 0.40 & 2.26 & 0.78 & 8.95 & 6.68 & 10.0 & 8.2 \\
\hline PI 433313 & 1.03 & 1.38 & 1.77 & 2.08 & 2.01 & 2.03 & 0.17 & 0.29 & 4.98 & 5.79 & 6.0 & 7.6 \\
\hline PI 433314 & 0.88 & 0.66 & 1.89 & 1.57 & 2.10 & 1.82 & 0.17 & 0.21 & 5.05 & 4.26 & 5.8 & 5.8 \\
\hline PI 433345 & 2.75 & 2,40 & 0.88 & 1.82 & 1.07 & 1.75 & 0.52 & 0.86 & 6.22 & 6.83 & 7.0 & 7.6 \\
\hline PI 433346 & 2.83 & 2.24 & 1.84 & 1.68 & 2.67 & 2.90 & 0.71 & 0.80 & 8.05 & 7.62 & 8.2 & 9.6 \\
\hline PI 441970 & 5.73 & 5.34 & 0.75 & 1.19 & 2.13 & 1.26 & 3.69 & 4.20 & 12.30 & 11.99 & 12.0 & 12.0 \\
\hline JP 3 & 0.77 & 0.27 & 1.83 & 2.06 & 2.68 & 2.86 & 0.40 & 0.20 & 5.69 & 5.40 & 6.4 & 6.4 \\
\hline JP 7 & 2.40 & 2.52 & 2.21 & 1.81 & 2.35 & 2.26 & 0.56 & 0.86 & 7.52 & 7.45 & 7.6 & 8.0 \\
\hline JP 8 & 2.40 & 1.68 & 1.71 & 2.33 & 2.57 & 2.45 & 0.37 & 0.27 & 7.05 & 6.73 & 7.6 & 8.0 \\
\hline JP 9 & 2.14 & 0.86 & 2.45 & 2.35 & 2.26 & 2.23 & 0.19 & 0.13 & 7.03 & 5.57 & 7.6 & 6.2 \\
\hline JP 11 & 1.88 & 1.48 & 2.45 & 2.42 & 2.73 & 2.69 & 0.37 & 0.35 & 7.43 & 6.93 & 7.6 & 8.0 \\
\hline JP 12 & 3.32 & 3.09 & 1.47 & 1.89 & 2.09 & 1.81 & 1.17 & 1.16 & 8.04 & 7.95 & 9.0 & 9.0 \\
\hline JP 13 & 1.77 & 1.37 & 2.05 & 1.79 & 2.24 & 1.83 & 0.44 & 0.39 & 6.50 & 5.37 & 7.0 & 8.0 \\
\hline JP 14 & 1.99 & 1.17 & 1.99 & 1.97 & 2.58 & 1.96 & 0.45 & 0.10 & 7.01 & 5.21 & 7.2 & 6.2 \\
\hline JP 15 & 1.57 & 1.23 & 2.63 & 2.56 & 2.74 & 2.27 & 0.19 & 0.20 & 7.12 & 6.27 & 7.2 & 7.0 \\
\hline JP 16 & 1.77 & 2.08 & 1.97 & 1.56 & 2.45 & 2.75 & 0.35 & 0.49 & 6.54 & 6.88 & 7.0 & 8.0 \\
\hline JP 17 & 0.92 & 0.37 & 2.96 & 1.37 & 1.68 & 1.28 & 0.09 & 0.06 & 5.66 & 3.08 & 6.0 & 4.0 \\
\hline JP 18 & 1.57 & 1.50 & 2.06 & 1.91 & 2.72 & 1.74 & 0.30 & 0.21 & 6.65 & 5.37 & 7.2 & 6.2 \\
\hline JP 19 & 0.96 & 1.12 & 1.80 & 2.04 & 1.86 & 2.63 & 0.10 & 0.17 & 4.72 & 5.96 & 5.4 & 6.2 \\
\hline JP 20 & 0.91 & 1.81 & 0.90 & 2.00 & 1.01 & 2.73 & 0.23 & 0.27 & 3.04 & 6.81 & 4.7 & 7.2 \\
\hline JP 21 & 0.60 & 1.37 & 1.71 & 2.24 & 1.87 & 2.39 & 0.10 & 0.24 & 4.28 & 6.24 & 5.0 & 7.2 \\
\hline JP 22 & 3.17 & 5.08 & 1.37 & 1.44 & 0.99 & 1.02 & 1.79 & 3.46 & 7.32 & 11.01 & 8.0 & 11.6 \\
\hline JP 60004 & 2.31 & 2.24 & 1.90 & 2.04 & 2.12 & 2.79 & 0.36 & 0.49 & 6.69 & 7.55 & 8.0 & 8.0 \\
\hline JP 70001 & 0.82 & 0.89 & 1.44 & 1.74 & 1.78 & 2.52 & 0.19 & 0.13 & 4.23 & 5.29 & 5.0 & 6.2 \\
\hline JP 70005 & 4.03 & 3.95 & 1.32 & 2.05 & 2.25 & 2.05 & 1.47 & 1.43 & 9.08 & 9.48 & 9.6 & 10.1 \\
\hline JP 610006 & 2.06 & 1.98 & 2.54 & 1.93 & 2.05 & 2.59 & 0.88 & 0.79 & 7.53 & 7.29 & 8.0 & 8.2 \\
\hline Granex 33 & 1.21 & 1.44 & 1.41 & 2.20 & 1.95 & .2 .22 & 0.24 & 0.40 & 4.80 & 6.25 & 5.0 & 7.2 \\
\hline Rio Estrella & 1.85 & 1.64 & 2.05 & 2.23 & 2.21 & 2.14 & 0.37 & 0.21 & 6.48 & 6.22 & 6.0 & 7.8 \\
\hline $\operatorname{LSD}_{0.05}{ }^{\mathrm{y}}$ & \multirow{2}{*}{\multicolumn{2}{|c|}{$\begin{array}{l}0.34 \\
0.35\end{array}$}} & \multirow{2}{*}{\multicolumn{2}{|c|}{$\begin{array}{l}0.27 \\
0.27\end{array}$}} & \multirow{2}{*}{\multicolumn{2}{|c|}{$\begin{array}{l}0.32 \\
0.32\end{array}$}} & \multirow{2}{*}{\multicolumn{2}{|c|}{$\begin{array}{l}0.12 \\
0.08\end{array}$}} & \multirow{2}{*}{\multicolumn{2}{|c|}{$\begin{array}{l}0.39 \\
0.29\end{array}$}} & \multirow{2}{*}{\multicolumn{2}{|c|}{$\begin{array}{l}0.3 \\
0.3\end{array}$}} \\
\hline $\operatorname{LSD}_{0.05^{x}}$ & & & & & & & & & & & & \\
\hline
\end{tabular}

2PI entries are U.S. Plant Introductions; JP entries are from the National Institute of Agricultural Sciences, Japan; 'Granex 33' from Asgrow Seed Co.; 'Rio Estrella' from Rio Colorado Seed Co.

$\mathrm{y}_{L S D}$ for differences between entry means for the same $S$ concentration.

${ } \mathrm{LSD}$ for differences between entry means for the two $S$ concentrations.

- TRS without invertase; fructose $=$ total fructose - fructose due to sucrose - fructose from fructans; glucose $=$ TRS without invertase - calculated fructose. Total NWSC concentration was the sum total of sucrose, glucose, fructose, and total fructans. Soluble solids were determined with a hand-held refractometer on the combined expressed juice from the five-bulb sample.

Data were tested by analysis of variance
(ANOVA) using the procedures of SAS (1985). Significantly different means were separated by least significant difference at $P$ $=0.05$. A correlation matrix and a Spearman rank correlation for entries between $S$ levels was calculated for all variables tested. ANOVA established significant differences $(P=0.05)$ between $S$ treatments for sucrose and glucose although average concentration differences were small. Average sucrose concentration was $3.84 \mathrm{~g} / 100 \mathrm{~g}$ fresh weight with the high-S treatment compared to $3.78 \mathrm{~g} / 100 \mathrm{~g}$ fresh weight with the low-S treatment. Average glucose concentration was slightly higher with the low-S treatment (1.95 $\mathrm{g} / 100 \mathrm{~g}$ fresh weight) than with the high-S treatment (1.86 g/100 g fresh weight). Differences between $\mathrm{S}$ treatments for fructose, fructans, and total NWSC were nonsignificant. 
Table 2. Correlation coefficients $(r)$ between nonstructural water-soluble carbohydrate variables across 60 onion entries grown under high $\left(4.0 \mathrm{meq} \cdot \mathrm{liter}^{-1}\right)$ and low $\left(0.1 \mathrm{meq} \cdot \mathrm{liter}^{-1}\right) \mathrm{S}$ nutrition.

\begin{tabular}{|c|c|c|c|c|c|}
\hline Variable & 1. & 2. & 3. & 4. & 5. \\
\hline & \multicolumn{5}{|c|}{ High $S$} \\
\hline 1. Sucrose & $\cdots$ & & & & \\
\hline 2. Fructose & $-0.38^{* *}$ & $\cdots$ & & & \\
\hline 3. Glucose & $-0.55^{* *}$ & $0.13^{\mathrm{NS}}$ & -- & & \\
\hline 4. Fructans & $0.86^{* *}$ & $-0.44^{* *}$ & $-0.59^{* *}$ & --- & \\
\hline 5. Total NWSC & $0.96^{* *}$ & $-0.28^{* *}$ & $-0.48^{* *}$ & $0.93^{* *}$ & $\cdots$ \\
\hline \multirow[t]{2}{*}{$\begin{array}{l}\text { 6. Soluble solids } \\
\text { content }\end{array}$} & $0.94^{* *}$ & $-0.36^{* *}$ & $-0.52^{* *}$ & $0.93^{* *}$ & $0.96^{* *}$ \\
\hline & \multicolumn{5}{|c|}{ Iow $S$} \\
\hline 2. Fructose & $-0.61^{* *}$ & --- & & & \\
\hline 3. Glucose & $-0.50^{* *}$ & $0.05^{\mathrm{NS}}$ & ... & & \\
\hline 4. Fructans & $0.92^{* *}$ & $-0.49^{* *}$ & $-0.53^{* *}$ & $\ldots$ & \\
\hline $\begin{array}{l}\text { 5. Total NWSC } \\
\text { 6. Soluble solids }\end{array}$ & $0.96^{* *}$ & $-0.49 * *$ & $-0.43^{* *}$ & $0.97^{* *}$ & $\cdots$ \\
\hline content & $0.94 * *$ & $-0.54^{* *}$ & $-0.48^{* *}$ & $0.94^{* *}$ & $0.96^{* *}$ \\
\hline
\end{tabular}

${ }^{x}$ Total nonstructural water-soluble carbohydrates.

Ns,**Not significant or significant at $P=0.01$, respectively.

Highly significant differences $(P=0.01)$ were found among entries for all variables tested. Total NWSC ranged from $20.1 \mathrm{~g} / 100$ $\mathrm{g}$ (PI168960) to $3.04 \mathrm{~g} / 100 \mathrm{~g}$ fresh weight (JP20) with the high-S treatment and from $18.7 \mathrm{~g} / 100 \mathrm{~g}$ (PI177244) to $3.08 \mathrm{~g} / 100 \mathrm{~g}$ fresh weight (JP17) with the low-S treatment (Table 1). These concentrations are representative of genotypic differences previously reported for dry-matter accumulation in onions, except for the lowest concentrations (Darbyshire and Henry, 1979; Darbyshire and Steer, 1988). Concentrations below $4.5 \mathrm{~g} /$ $100 \mathrm{~g}$ fresh weight are uncommon. Total NWSC were highly correlated with SSC (Table 2). SSC has been correlated with drymatter percentage in onions (Mann and Hoyle, 1945; Nieuwhof et al., 1973).

Sucrose ranged between $11.3 \mathrm{~g} / 100 \mathrm{~g}$ fresh weight (PI168960) and $0.60 \mathrm{~g} / 100 \mathrm{~g}$ fresh weight (JP21) with the high-S treatment and between $9.20 \mathrm{~g} / 100 \mathrm{~g}$ (PI168961) and 0.37 $\mathrm{g} / 100 \mathrm{~g}$ fresh weight (JP17) with the low-S treatment (Table 1). This variation among entries with either of the $\mathrm{S}$ treatments was greater than previously reported for sucrose concentrations (Darbyshire and Henry, 1979; Suzuki and Cutcliffe, 1989). Entries with higher and lower sucrose concentration were identified. Total fructans ranged from 8.90 $\mathrm{g} / 100 \mathrm{~g}$ fresh weight (PI182138) to $0.09 \mathrm{~g} /$ $100 \mathrm{~g}$ fresh weight (JP17) at the high-S treatment and from $7.92 \mathrm{~g} / 100 \mathrm{~g}$ fresh weight (PI177244) to $0.06 \mathrm{~g} / 100 \mathrm{~g}$ fresh weight (JP17) at the low-S treatment. These concentrations are representative for fructan concentrations previously reported (Darbyshire and Henry, 1979; Suzuki and Cutcliffe, 1989). Fructan concentration has been correlated with total dry-matter percentage in onions (Darbyshire and Henry, 1979). My data indicate that either total fructans or sucrose are highly correlated with total NWSC (Table 2). The higher the fructan or sucrose concentration in an entry, the higher the total NWSC concentration. There were exceptions to the association, however, which could allow a breeder to select for deviant sucrose or total fructan concentrations. For example, PI181008 and PI261768 had high sucrose concentrations for mid-level total NWSC entries with the high-S treatment. With the low$S$ treatment, PI261768 had a high sucrose concentration for mid-level total NWSC entries while PI249540 and PI414931 had high sucrose concentrations for low total NWSC entries.

Fructose concentration ranged from 3.52 $\mathrm{g} / 100 \mathrm{~g}$ fresh weight (PI354092) to $0.05 \mathrm{~g} /$ $100 \mathrm{~g}$ fresh weight (PI247067) with the high$\mathrm{S}$ treatment and from $3.01 \mathrm{~g} / 100 \mathrm{~g}$ fresh weight (PI430371) to $0.23 \mathrm{~g} / 100 \mathrm{~g}$ fresh weight (PI274781) with the low-S treatment. Glucose concentrations ranged from $3.35 \mathrm{~g} /$ $100 \mathrm{~g}$ fresh weight (PI251021) to $0.14 \mathrm{~g} / 100$ $\mathrm{g}$ fresh weight (PI177244) with the high-S treatment and from $3.11 \mathrm{~g} / 100 \mathrm{~g}$ fresh weight (PI251021) to $0.30 \mathrm{~g} / 100 \mathrm{~g}$ fresh weight (PI168960 and PI174019) with the low-S treatment (Table 1). This range of fructose and glucose concentrations was higher and lower than that previously reported (Suzuki and Cutcliffe, 1989). Reducing sugar concentrations were also reported to be low in cultivars that contain a high percentage of dry matter (Darbyshire and Henry, 1979). In my study, the correlations of fructose and glucose with total NWSC were poor, although highly significant (Table 2). For high total NWSC entries (>14 g/100 g fresh weight), fructose ranged from $0.23 \mathrm{~g} / 100 \mathrm{~g}$ fresh weight (PI274781) to $1.88 \mathrm{~g} / 100 \mathrm{~g}$ fresh weight (PI177244) with the low-S treatment and from $0.46 \mathrm{~g} / 100 \mathrm{~g}$ fresh weight (PI174019) to $3.52 \mathrm{~g} / 100 \mathrm{~g}$ fresh weight (PI354092) with the high-S treatment. Differences between many of the high and low total NWSC entries were nonsignificant for fructose concentrations. Similar results were found for glucose concentrations.

Monosaccharide concentrations in onion have been used as predictors of bulb storage life. Rutherford and Whittle (1984) indicated that high fructose concentrations in bulb scales at harvest would increase the storage life of 'Robusta'. This relationship may be cultivar specific. Of the entries evaluated in our study, PI430371 had the highest fructose concentration with the low-S treatment, but had an extremely short storage life (data not shown).
Suzuki and Cutcliffe (1989) have also shown that the water-soluble carbohydrates are poor predictors for onions with medium to long storage life but may be useful in predicting cultivars with a very short storage life.

ANOVA also established significant differences $(P=0.01)$ for the interaction between $S$ and entry for all variables tested. Thirty-five of the 60 entries had higher total NWSC concentrations with the high-S treatment while 25 had higher concentrations with the low-S treatment (Table 1). Fifteen entries had total NWSC concentrations that were nonsignificant for differences between the high- and low-S treatments. Certain entries, however, were greatly influenced by $\mathrm{S}$ nutrition. PI168960, PI249540, PI354092, and JP17 had much higher total NWSC concentrations with the high-S treatment than with the low-S treatment, while JP20, JP21, and JP22 had much higher total NWSC concentrations with low $\mathrm{S}$ than with the high-S treatment. In addition, entries with high NWSC concentrations were as likely to be affected by S treatment as were low-NWSC entries. Of the commercial cultivars tested, 'Granex 33' had significantly higher total NWSC with the low-S treatment while 'Rio Estrella' was unaffected by $\mathrm{S}$ treatment. Similar responses in the entry x $\mathrm{S}$ treatment interaction were found for sucrose, fructose, glucose, and total fructans. Spearman rank correlations were low but highly significant ( $P=0.01)$ for sucrose $\left(\mathrm{r}_{\mathrm{s}}=0.56\right)$, fructans $\left(r_{s}=0.33\right)$, and NWSC $\left(r_{s}=0.43\right)$ for entries between $\mathrm{S}$ levels. Rank correlations were low and nonsignificant for fructose $\left(r_{s}\right.$ $=0.27)$ and glucose $\left(r_{s}=0.10\right)$.

Sulfur nutrition affected the concentration of total and individual NWSC in onion germplasm. Greater variation was found for sucrose, fructose, and glucose concentrations than previously reported. A significant $\mathrm{S} \times$ entry interaction was found. Therefore, when selecting onions for total or individual NWSC, it is important that it be done at S concentrations indicative of targeted production areas.

\section{Literature Cited}

Bacon, J.S.D. 1957. The water-soluble carbohydrates of the onion, Allium cepa L. Biochem. J. 67:5

Bajaj, K.L., G. Kaur, J. Singh, and S.P.S. Gill. 1980. Chemical evaluation of some important varieties of onion (Allium cepa L.). Qualitas Plant. Plant Foods Hum. Nutr. 30:117-122.

Blakeney, A.B. and L.L. Mutton. 1980. A simple colorimetric method for the determination of sugars in fruit and vegetables. J. Sci. Food Agr. 31:889-897.

Bose, S. and A.N. Shrivastava. 1961. Soluble carbohydrates from onion (Allium cepa Linn.). Sci. Cult. 27:253.

Darbyshire. B. and R.J. Henry. 1978. Changes in the carbohydrate content of onion bulbs stored for various times at different temperatures. J. Hort. Sci. 53:195-201.

Darbyshire, B. and R.J. Henry. 1979. The association of fructans with high percentage dry weight in onion cultivars suitable for dehydrating. J. Sci. Food Agr. 30:1035-1038. 
Darbyshirc, B. and B.T. Steer. 1988. Carbohydrate biochemistry. vol. 3, p. 1-16. In: H.D. Rabinowitch and J.L. Brewster (eds.). Onions and allied crops. CRC Press, Boca Raton, Fla.

Freeman, G.G. and N. Mossadeghi. 1970. Effect of sulphate nutrition on flavour components of onion (Allium cepa). J. Sci. Food Agr. 21:610615.

Hoagland, D.R. and D.R. Arnon. 1950. The water culture method for growing plants without soil. California Agr. Expt. Sta. Circ. 347.

Jones, H.A. and L.K. Mann. 1963. Onions and their allies. Botany, cultivation, and utilization. Interscience, New York.

Lancaster, J.E. and M.J. Boland. 1988. Flavor biochemistry, p. 33-72. In: H.D. Rabinowitch and J.L. Brewster (eds.). Onions and allied crops. vol. 3. CRC Press. Boca Raton. Fla.

Mann, L.K. and E.J. Hoyle. 1945. Use of the refractometer for selecting onion bulbs high in dry matter for breeding. Proc. Amer. Soc. Hort. Sci. 46:285-292.

Nieuwhof, M., J.W. DeBruyn, and F. Garretsen. 1973. Methods to determine solidity and dty matter content of onions (Allium cepa L.). Euphytica 22:39-47.

Nilsson, T. 1980. The influence of the time of harvest on the chemical composition of onions. Swedish J. Agr. Res. 10:77-88.

Paterson, D.R. 1979. Sulfur fertilization effects on onion yield and pungency. Texas Agr. Expt. Sta. Prog. Rpt. 3551
Pontis, H. 1966. Observations on the de novo synthesis of fructosans in vivo. Arch. Biochem. \& Biophys. 116:416-424

Rabinowitch, H.D. 1988. Genetics and breeding: State of the art or too slow but not too late. Eucarpia 4th Allium Symp. Wellsbourne, Warwick, U.K. p. 57-69.

Rutherford, P.P. and R. Whittle. 1984. Methods of predicting the long-term storage of onions. J. Hort. Sci. 59:537-543.

SAS Institute. 1985. SAS user's guide: Statistics. version 5 (ed.) SAS Institute, Cary, N.C.

Suzuki, M. and J.A. Cutcliffe. 1989. Fructans in onion bulbs in relation to storage life. Can. J. Plant Sci. 69:1327-1333.

HORTSCIENCE 27(1):55-57. 1992.

\title{
Heritable Differences in Postproduction Quality of Pelargonium $\times$ domesticum
}

\author{
C. Frederick Deneke, Leon J. Glicenstein ${ }^{2}$, Kathleen B. Evensen ${ }^{3}$, \\ and Richard Craig ${ }^{4}$ \\ Department of Horticulture, The Pennsylvania State University, \\ University Park, PA 16802
}

Additional index words. breeding, genetics, petal abscission, flowering potted plants, regal pelargonium, Martha Washington geranium

\begin{abstract}
The postproduction quality of 33 cultivars and 178 Pennsylvania State Univ. breeding lines of Pelargonium $\times$ domesticum L.H. Bailey was evaluated in a simulated consumer environment. Petal abscission was the primary factor that reduced postproduction ratings (PPR). The heterozygosity of some cultivars was indicated by the range of PPR of progeny from self-pollinations. This range of PPR implies that $P$. $x$ domesticum has genetic variation for postproduction quality that can be used in a breeding and selection program. Few progeny with high PPR were produced from either self- or cross-pollinations involving parents with low PPR. Many of the superior progeny resulted from parents with high PPR. Therefore, progeny with improved postproduction quality can be developed by selecting parents with high PPR.
\end{abstract}

Postproduction quality of several floricultural crops has been shown to have a strong genetic component. The vase life of 77 hybrid cultivars of tulips ranged from 3 to $>6$ days (Benschop and DeHertogh, 1969). Harbaugh and Waters (1979) noted differences

Received for publication 24 Jan. 1991. Accepted for publication 15 Aug. 1991. Contribution no. 170 Dept. of Horticulture. This work was supported in part by the Fred C. Gloeckner Foundation and Oglevee Associates, Inc. Mention of a trademark, proprietary product, or vendor does not imply endorsement by The Pennsylvania State University, nor criticism of similar ones not mentioned. The cost of publishing this paper was defrayed in part by the payment of page charges. Under postal regulations, this paper therefore must be hereby marked advertisement solely to indicate this fact.

'Assistant Professor, Dept. of Horticulture, Auburn Univ.. AL 36849-5408.

2Present address: Yoder Brothers, Inc., P.O. Box 218, Chualar, CA 93925.

${ }^{3}$ Associate Professor.

${ }^{4}$ Professor. among cultivars of several species of flowering potted plants for duration of flowering. Petal abscission following mechanical shaking of detached inflorescences of 35 cultivars of seed-propagated zonal geranium $(P$. $\times$ hortorum L.H. Bailey) ranged from $10 \%$ for 'Ringo Rose' to $39 \%$ for 'Sooner Red' (Armitage et al., 1980).

Before selecting for postproduction quality, phenotypic characters must be identified that are good indicators of postproduction quality. For example, van Eijk and Eikelboom (1976) observed that the vase life of cut tulips was strongly correlated with flower longevity on plants grown in the field; therefore, initial selections could be made in the field. Most phenotypic characters responsible for vase life of tulips are additive; therefore, superior progeny could be developed by effective selection of the parents (van Eijk and Eikelboom, 1986). An important consideration in selecting and breeding for improved postproduction quality is the definition of a standard evaluation environment, since postproduction quality is influenced by in- teractions between a genotype and the environment (de Jong, 1979; Sparnaaij, 1979).

Because of its large showy flowers, $P$. $\times$ domesticum (regal pelargonium or Martha Washington geranium) has commercial potential as a flowering potted plant. However, its popularity may be limited by petal abscission following exposure to ethylene (Deneke, 1988) or shipping stress (R. Oglevee, personal communication). In the breeding program at The Pennsylvania State Univ., P. $\times$ domesticum has been selected for such characteristics as floret color and size, number of inflorescenes, time to anthesis, heat tolerance, and plant form. In addition, enhanced postproduction quality has been used as a selection criterion. Development of cultivars with enhanced postproduction characteristics may increase the marketability of P. $\times$ domesticum.

Information on the inheritance of horticultural characteristics, particularly postproduction quality, is required for future breeding efforts. Valid inheritance studies require both inbred lines and large populations of progeny. However, P. $\times$ domesticum displays low seed production in selfand cross-pollinations and is believed to be a polyploid with a complex parentage (Craig, 1982; Hanniford and Holcomb, 1982). In addition, we have observed in-

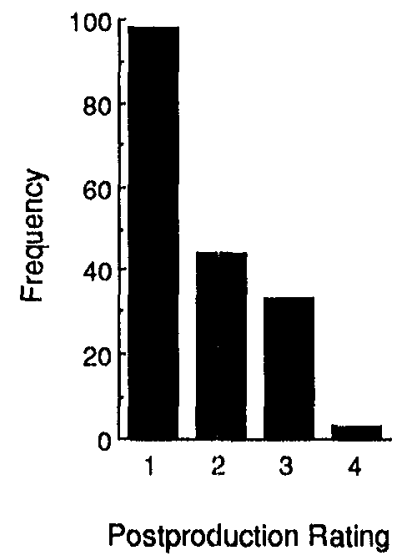

Fig. 1. Distribution of postproduction ratings of $178 P$. $\times$ domesticum progeny from highest (1) to lowest (4) amount of petal abscission after 3 weeks in a simulated consumer environment. 